\title{
Extensão universitária: lugar de encontro entre a educação e as diversidades
}

\author{
University community projects: the meeting place between education and \\ diversity
}

\author{
Ana Célia de Sousa Santos ${ }^{1}$ \\ 1 Professora. Universidade Estadual do Piauí (UESPI), Brasil. E-mail: aceliasantos@gmail.com
}

Recebido em: 10/03/2015 | Aprovado em: 10/06/2015

DOI: $10.12957 /$ interag.2015.15508

\begin{abstract}
Resumo
O Projeto de Extensão "Rodas de Culturas" nasceu do Intercâmbio Científico Cultural entre a Universidade dos Estudos de Verona/Itália, a Universidade Estadual do Piauí - UESPI e a Universidade Federal do Piauí. É um espaço de produção de práticas e saberes que se concretizam na relação entre a universidade e a Associação de Produção "Mulheres Perseverantes, da comunidade Parque Eliane. Tem como objetivo geral promover a troca de saberes, através da organização do espaço "Rodas de Culturas", possibilitando discussão, reflexões e produção de conhecimentos sobre a cultura, as relações de gênero, geracionais, étnica e ambiental. Tem como metodologia de trabalho a educação popular e a Pedagogia Feminista e propõe a discussão de temáticas relacionadas à educação e às diversidades, com especificidade para as questões de gênero. Assim, a extensão universitária possibilita o encontro entre a educação e a diversidade, tornando-se um espaço de construção de saberes com base em princípios que conduzem alunos/as, professores/as e a comunidade à emancipação. Esses estudos foram fundamentados em Libâneo, Louro, Sardenberg, Gohn, Paulo Freire, Melo Neto, dentre outros. Desse modo, este projeto proporcionou a construção de práticas educativas que favorecem o desenvolvimento de novas posturas diante do contexto das diversidades. Contribui, também, com a discussão dessa temática trazendo à "Roda de Culturas" vivências e convivências que permitem o questionamento das atuais práticas sociais e educativas, assim como, a reflexão sobre as relações de gênero, possibilitando a construção de relações mais justas e igualitárias.
\end{abstract}

Palavras-chave: Educação; Extensão; Diversidades.

\begin{abstract}
The Community Project and space "Culture Wheels" was born due to the Cultural Scientific Exchange between the Università degli Studi di Verona/Italy, the State University of Piauí - UESPI and the Federal University of Piaui - UFPI. It is a space for producing knowledge and practice that arise in the relationship between the university and the Production Association "Persevering Women ", of the Eliane Parque community. Its general objective is to promote the exchange of knowledge through the organization of the space "Culture wheels", enabling discussion, reflection and production of knowledge about culture, gender, generational, ethnic and environmental relations. Its methodology of work is based on the popular education and the Feminist Pedagogy and proposes the discussion of issues related to education and diversity, with specificity for gender issues. Thus, the university community project enables the meeting between education and diversity, becoming a space of knowledge construction based on principles that lead students, teachers and the community to emancipation. These studies were based on the ideas of Libâneo, Louro, Sardenberg, Gohn, Paulo Freire, Melo Neto, among others. This project has provided the building of educational practices that favor the development of new attitudes on the context of diversity. It also contributes to the discussion of this subject bringing to the "Culture Wheel" experiences that allow the questioning of current social and educational practices, as well as the reflection on gender relations, allowing the construction of more egalitarian and fair relations.
\end{abstract}

\section{Keywords: Education; Community Project;} Diversities.

Área temática: Educação.

Linha de extensão: Organização da Sociedade Civil e Movimentos sociais. 


\section{Introdução}

O Projeto de Extensão "Rodas de Culturas" nasceu do Intercâmbio Científico Cultural entre a Universidade dos Estudos de Verona, a Universidade Estadual do Piauí - UESPI e a Universidade Federal do Piauí - UFPI. É desenvolvido desde 2004 no PREMEM/Norte e no Parque Eliane - comunidade localizada na zona sul de Teresina.

O projeto denominado de Rodas de Culturas: lugar de encontro entre a educação e as diversidades é um espaço de produção de práticas e saberes que se concretizam na relação entre a universidade e a Associação de Produção "Mulheres Perseverantes, da comunidade Parque Eliane. Tem como objetivo geral promover a troca de saberes, através da organização do espaço "Rodas de Culturas", possibilitando discussão, reflexões e produção de conhecimento sobre a cultura, as relações de gênero, geracionais, étnica e ambiental. Como objetivos específicos, organizar o espaço "Rodas de Culturas", possibilitando o encontro de mulheres, homens, idosos e crianças para discutir temáticas relacionadas à educação e às diversidades, realizar encontros com as mulheres e homens para discutir sobre educação, cultura, e as relações de gênero, produzir artigos científicos sobre as temáticas em questão, oferecer aulas de capoeira e realizar seminários para divulgação e avaliação das ações desenvolvidas.

O desenvolvimento dessas ações possibilita a integração entre a universidade e a comunidade, favorecendo a relação entre ensino, pesquisa e a extensão.

\section{O lugar de encontro entre a educação e as diversidades}

As temáticas relacionadas à educação e às diversidades trazem à tona questionamentos que nos fazem refletir sobre qual sociedade estamos construindo e como queremos construí-la. Faz-nos pensar sobre que desenvolvimento e que tipo de relações econômicas, sociais, políticas e educacionais são possíveis numa nova sociedade.

Assim, é necessário compreendermos a educação como os processos formativos que se desenvolvem na vida familiar, na convivência humana, no trabalho, nas instituições de ensino e pesquisa, nos movimentos sociais e organização da sociedade civil e nas 
manifestações culturais, proporcionando o desenvolvimento de vários olhares sobre o mundo e as pessoas. ${ }^{1}$

Esses processos correspondem a, [...] toda modalidade de influências e inter-relação que convergem para a formação de traços de personalidade social e do caráter, implicando uma concepção de mundo, ideias, valores, modos de agir, que se traduzem em convicções ideológicas, morais, políticas, princípios de ação frente a situações reais e desafios da vida prática. $^{2}$

A partir desse entendimento é compreensível afirmar que, sendo a educação um processo de múltiplas práticas, possui também sujeitos diversos e contextos variados. Dessa forma, torna-se necessário desenvolver práticas educativas que valorizem as diversidades construídas pelos diferentes sujeitos, e ao mesmo tempo criem espaços de diálogo e problematização dessas diferenças.

Assim, não é possível pensar nas relações sociais como um processo único, uniforme e linear, porque isso levaria à eliminação da diversidade das culturas e das experiências, limitando assim a capacidade criadora da humanidade. Além disso há um movimento de diversificação cultural estimulando a consciência de que a civilização humana é um mosaico de culturas diferentes e que o estilo de vida próprio de cada povo constitui um valor, um direito, uma responsabilidade, sendo que tal evolução é fruto da emancipação humana. ${ }^{3}$ Integrar as questões étnicas, de geração, gênero, ambientais, educacionais e culturais nas estratégias globais de desenvolvimento da sociedade, bem como nas pautas mais efetivas de ação, deveria ser uma opção política de orientação do processo de reflexão e efetivação de um novo jeito de ser e estar em grupo.

Nesta perspectiva, faz-se necessário que consideremos a cultura como um fator preponderante para a discussão da inclusão e do respeito às diferenças e às diversidades. Neste sentido, a cultura passa a ser criadora de novos parâmetros no cultivo da diversidade - fontes de autorreconhecimento e autoestima dos diferentes povos. A expressão "diversidade", ao mesmo tempo em que pode indicar a percepção quase que óbvia da própria variedade humana, física, social e ambiental presente em nossa 
sociedade, traz em si um conjunto múltiplo e complexo de significados. No campo das ciências sociais, o termo é, em geral, utilizado para descrever a heterogeneidade de culturas que tem marcado a atualidade, por oposição ao modelo de Estado-nação moderno, liberal e ocidental, que se afirmou "sobre o pressuposto da homogeneidade cultural organizada em torno de valores universais, seculares e individuais". ${ }^{4}$

Enquanto direito à diferença, a diversidade articula-se à exigência de reconhecimento na esfera pública e política de diferentes grupos e movimentos sociais.

No caso do Brasil, essa reivindicação tem sido trazida, principalmente, por alguns setores do movimento feminista e do movimento negro, a partir dos anos 80 , intensificando-se nos anos seguintes, quando passa a envolver também os movimentos indígenas, de livre orientação sexual e das pessoas com deficiência.

A trajetória de luta pela inclusão, pelo respeito às diferenças e às diversidades, na nossa compreensão, envolve a inclusão de novas temáticas - gênero, raça/etnias, geração, orientação sexual, reconhecimento das diferenças ambientais - sobretudo a discussão de qual educação queremos, qual currículo e quais práticas educativas são necessárias para implementação de novas posturas.

Assim, compreendemos as práticas educativas como um fenômeno social e universal que acontece de modo intencional ou não, sendo necessário na existência e funcionamento de todas as sociedades. Sendo assim, a prática educativa [...] não é apenas uma exigência da vida em sociedade, mas também o processo de prover os indivíduos dos conhecimentos e experiências culturais que os tornam aptos a atuar no meio social e a transformá-lo em função de necessidades econômicas, sociais e políticas da coletividade. ${ }^{2}$

Desse modo, devemos proporcionar a construção de práticas educativas que favoreçam o desenvolvimento de novas posturas diante do contexto das diversidades. Tais enfoques devem ter como pressupostos básicos o respeito à diversidade, buscando a "superação de mecanismos que exclui e segrega o/a 'outro/a' que possui identidades sociais 
diferenciadas e não correspondentes à normalidade do 'sujeito do iluminismo' caracterizado, sobretudo por ser branco, cristão, europeu e heterossexual”. 5

Sendo assim, o reconhecimento do direito à diferença é um claro abandono da política assimilacionista/integracionista que imperou praticamente todo o período colonial e grande parte do período republicano, precisamente até a década de 80 do século passado. Tal postura via como necessário e inevitável o desaparecimento das culturas indígenas, negras e quilombolas. Esta teoria orientou a política do Estado brasileiro durante todo este longo período e foi aos poucos sendo superado e desconstruído. ${ }^{6}$

Desse modo, o reconhecimento do direito à diferença é, pois, um princípio básico de uma sociedade democrática - não existe democracia substantiva sem pluralidade. A sociedade brasileira, em particular, é pluriétnica, multirracial bastante diferenciada regionalmente e, portanto, o respeito a essa diversidade é fundamental para a construção da democracia e do desenvolvimento de que tanto falamos.

Assim, a Associação de Produção "Mulheres Perseverantes" do Parque Eliane é um espaço favorável a esta discussão haja vista ser o lócus do encontro entre mulheres negras, brancas e homens de diferentes gerações, com qualificação e escolarização diversas que almejam o aumenta da renda, a melhoria da qualidade de vida e a inclusão de seus filhos/as na vida da comunidade, assim como no acesso aos bens e serviços oferecidos pelo Estado.

O Parque Eliane situado na zona sul de Teresina, criado em 2001, foi resultado de uma ocupação de terra. Hoje as mulheres se organizam na Associação e as crianças na Casa de Artes e Culturas - CAC para atendimento a Crianças e outros agentes comunitários (mulheres, jovens e homens). Todas essas atividades se desenvolveram com suportes possibilitados pelo convênio entre a UFPI, a UESPI e a Universidade dos estudos de Verona (Itália), realizando atividades desde julho de 2005.

Desse modo, este projeto de extensão contribui na continuidade de trabalhos já desenvolvidos que resultou em diversos trabalhos científicos como monografias, trabalhos 
de conclusão de curso, dissertação de mestrado, dentre outros apresentados em eventos científicos e em livros. Assim, também, poderá contribuir com a discussão dessa temática trazendo à Roda de Culturas vivências e convivências que permitirá o questionamento das atuais práticas sociais e educativas, assim como para a construção de relações mais justas e igualitárias entre mulheres e homens.

\section{Relações de gênero e educação: contribuições para a extensão universitária}

Historicamente, os processos educativos têm sido caracterizados por práticas que reforçam a educação sexista, privilegiam os homens e contribuem para a manutenção da sociedade patriarcal. Com essa discussão propomos uma reflexão sobre a Pedagogia Feminista no sentido de contribuir com o empoderamento e emancipação de mulheres, desconstruindo paradigmas que tendem a levá-las à submissão, inviabilizando suas práticas. ${ }^{7}$

A Pedagogia Feminista é uma metodologia de trabalho popular que tem como base o trabalho com mulheres. Esse trabalho tem sido organizado por ONGs, igrejas, sindicatos e até núcleos acadêmicos junto a diferentes categorias de mulheres. A Pedagogia Feminista é entendida como o conjunto de princípios e práticas que visa conscientizar indivíduos, tanto homens como mulheres, da ordem patriarcal vigente em nossa sociedade, dando-lhes instrumentos para superá-la e, assim, atuarem de modo a que construam a equidade entre os sexos. ${ }^{8}$

Essa metodologia de trabalho parte do pressuposto de que vivemos numa sociedade marcada por desigualdades nas relações entre mulheres e homens. Nesse caso, o controle é definido por relações de poder, podendo na maioria das vezes invisibilizar as mulheres como construtoras de sua própria história e de suas práticas cotidianas. Assim, a Pedagogia Feminista deve "intentan ser denuncias de las más diversas opresiones. Sería una manera de pensar una pedagogía de los oprimidos, oprimidas, [...]; una pedagogía que nos permita volvernos sujetos de nuestra propia marcha, de su rumbo, de la renovación de sus metas y de las formas y ritmos que elegimos para caminar". 
As relações de gênero produzidas pelo modelo patriarcal de organização da sociedade encontram suporte na discussão de classe social, surgida com o capitalismo. No entanto, uma série de mudanças na natureza dessas relações é introduzida pela emergência de forças feministas, fomentada pelas transformações sociais, políticas, econômicas e culturais, nos últimos 40 anos. $\mathrm{O}$ aparecimento de novos paradigmas questionando o patriarcado como categoria que situa as mulheres muito abaixo dos homens, em todas as áreas da convivência humana e a racionalidade como conceito universal, introduz o estudo sobre a subjetividade e a construção do psiquismo humano, como novos aspectos que definem formas de atuação de homens e mulheres em igualdade de condições respeitando as suas diferenças vem proporcionando novos estudos e discussões em torno desta temática. ${ }^{10}$

O modelo feminista de educação questiona o dualismo que permeia as atuais relações entre mulheres e homens. Nesse caso, [...] a lógica subjacente a esta proposta se assenta em alguns dualismos "clássicos": competição/cooperação; objetividade/subjetividade; ensino/aprendizagem; hierarquia/igualdade - dualismo em que o primeiro termo representa o modelo androcêntrico de educação e o segundo termo aponta para a concepção feminista. ${ }^{7}$

Propõe, ainda, um conjunto de estratégias e procedimentos que rompe com a lógica de que o saber se encontra apenas naquele que é fonte de autoridade e transmissor único de conhecimento. Propõe, então, a valorização das várias vozes, sendo o diálogo sua dinâmica problematizadora, no qual todas e todos são igualmente falantes e ouvintes, capazes de expressar diferentes saberes. As situações de aprendizagens são momentos privilegiados nos quais todas/os são levadas/os a construírem conhecimentos de forma cooperativa.7 Nesta perspectiva, essas atrizes e atores sociais passam a acreditar em seus saberes, dando sentido às suas falas e aos seus desejos.

A Pedagogia Feminista pretende ser emancipatória porque possibilita a conscientização, a libertação e a transformação das/os sujeitas/os e de sua realidade. Nessa perspectiva, [...] a educação libertadora, problematizadora, já não pode ser o ato de depositar, ou de narrar, 
ou de transferir, ou de transmitir "conhecimentos" e valores [...] mas um ato cognoscente. Como situação gnosiológica, em que o objeto cognoscível, em lugar de ser o término do ato cognoscente de um sujeito, é o mediatizador de sujeitos cognoscentes, [...] a educação problematizadora coloca, desde logo, a exigência da superação da contradição educadoreducandos $\left[\ldots . .{ }^{11}\right.$

Além de libertadora, transformadora e dialógica, essas práticas educativas devem dar poder às mulheres de forma a permitir, tanto às práticas como às relações interpessoais, a utilização de estratégias de "superação" do estado de submissão e de ausência do exercício do poder entre elas. Pensando assim, [...] as relações sociais são sempre relações de poder e que o poder se exerce mais na forma de rede do que em um movimento indirecional, então não será possível compreender as práticas como isentas desses processos. A construção de uma prática educativa não-sexista necessariamente terá de se fazer a partir de dentro desses jogos de poder. ${ }^{7}$

Desse modo, as possibilidades de recriação, através da Pedagogia Feminista, podem permitir às mulheres a (re) construção de identidades tanto individual quanto coletivas, levando-as a rever suas posturas diante de sua subordinação à cultura hegemônica. É esta Pedagogia que "recreamos las identidades colectivas, no como límites sino como puentes, no para quedar subordinadas desde ellas frente a la identidad hegemónica, sino como espacio de constitución de nuestras subjetividades, haciéndolas desafiantes del orden individuais organizado desde la dominación".

Nesse caso, o espaço onde vivem as "Mulheres Perseverantes", do Parque Eliane (Teresina-PI), torna-se espaço político de construção de novas práticas do poder. As transformações que produzem partem de práticas cotidianas e das vivências dessas mulheres, possibilitando, a elas mesmas, um exercício de autocrítica.

$\mathrm{Na}$ perspectiva de gênero, o trabalho educativo implica, portanto, em reconhecer as assimetrias de poder entre mulheres e homens na sociedade, no cotidiano e em todas as dimensões da vida. "Assim, a prática educativa orientada por tal perspectiva corrobora 
para o alcance do empoderamento, de democracia, autonomia e liberdade das mulheres e, consequentemente, para a justiça social". ${ }^{12}$

Nesse sentido, temos um grande desafio, como educadora/o popular, contribuir para a construção de uma nova sociedade, como parte instituinte desse processo. Assim, o processo de formação dos indivíduos deve ter quatro objetivos estratégicos: o ser, que se refere às competências individuais; o conhecer, que diz respeito ao desenvolvimento de competências para saber o que conhecer; o conviver, que está na esfera interpessoal, na dimensão da sociabilidade dos indivíduos, no plano das relações que ele desenvolve com o/a outro/a, com as pessoas, com a cidade, com a nação; e o fazer, que se relaciona às competências produtivas, habilidades básicas, específicas e de gestão. ${ }^{13}$

Esta autora destaca, ainda, a necessidade de que a metodologia da EP tenha mão dupla em direção ao indivíduo e à estrutura da sociedade. Sobre isto, Paulo Freire esclarece que “a conscientização está evidentemente ligada à utopia, implica a utopia. Quanto mais conscientizados(as) nos tornamos, mais capacitados estamos para sermos anunciadores e denunciadores, graças ao compromisso que assumimos". ${ }^{1}$

Nesta perspectiva, trabalhar esse novo jeito de educação é um desafio prazeroso, pois, leva-nos a identificar-nos com a possibilidade de nos relacionarmos com novos sujeitos sociais, capazes de nos desafiar ao contínuo aprender e ensinar, lendo e relendo o mundo e as pessoas com novo olhar. É o que oportuniza o trabalho com as mulheres do Parque Eliane, pois, reafirma que é através da organização, do respeito às diferenças e dos processos educativos críticos e reflexivos que construímos novas possibilidades de ver a vida com outro olhar. Nisso consiste o nosso compromisso com a Educação Popular. Esse modo de ser, também nos anima para continuarmos contribuindo com a construção de uma nova sociedade.

Desse modo, de acordo com a concepção da Pedagogia Feminista e baseada nos princípios da Educação Popular, podemos introduzir as/os sujeitas/os numa nova prática social, sendo necessário, portanto, práticas cotidianas que envolvam processos de empoderamento e de emancipação. 
Com esse entendimento é possível compreender o que significa empoderamento, ao buscar refletir sobre os seus múltiplos sentidos e consequências para um projeto de extensão.

Com esse entendimento é imprescindível que se compreenda o que significa empoderamento, buscando refletir sobre os seus múltiplos sentidos e consequências para um projeto de intervenção. Empoderamento origina-se da palavra inglesa "empowerment" que é $[. .$.$] o meio pelo qual as pessoas adquirem maior controle sobre as decisões que$ afetam suas vidas; ou como as mudanças em direção a uma maior igualdade nas relações sociais de poder, por exemplo, nas relações com quem detém recursos, legitimidade, autoridade e/ou influência. ${ }^{14}$

Complementando essa ideia, o "empowerment" significa o aumento do poder e da autonomia pessoal e coletiva de indivíduos e grupos sociais nas relações interpessoais e institucionais, especialmente daqueles submetidos a relações de opressão, discriminação e dominação social. Ainda, segundo o autor, um dos aspectos fundamentais do empowerment diz respeito às possibilidades de que a ação local fomente a formação de alianças políticas capazes de ampliar o debate da opressão no sentido de contextualizá-la e favorecer a sua compreensão como fenômeno histórico, estrutural e político. $\mathrm{O}$ trabalho comunitário, que busca o empowerment, contribui para o surgimento de um tecido social fortalecido pelas interações que promovem, evidenciadas pelo caráter dialético e contraditório presente em todas as relações sociais e que, essencialmente, confere poder ao sujeito social envolvido. ${ }^{14}$

O "empowerment" é um conceito complexo, apresentando diversas maneiras de interpretação. Para conceituá-lo, alguns autores utilizam-se de noções de distintos campos do conhecimento. É uma ideia que tem raízes nas lutas pelos direitos civis, no movimento feminista e na ideologia da "ação social", presentes nas sociedades dos países desenvolvidos, na segunda metade do século XX. Nos anos 1970, este conceito é influenciado pelos movimentos de autoajuda e, nos anos da década de 1980, pela psicologia comunitária. $\mathrm{Na}$ década de 90 recebe o influxo de movimentos que buscam 
afirmar o direito da cidadania sobre distintas esferas da vida social, entre as quais, a prática médica, a educação em saúde e o ambiente físico.

Essa dificuldade de conceituação está refletida no modo com que a referida categoria vem sendo traduzida em textos nos idiomas português e espanhol: para alguns é sinônimo de "empoderamento", "apoderamento" e, para outros/as, de "emancipación". Significados distintos, uma vez que "apoderar" é sinônimo de dar posse, "domínio de", "apossar-se", "assenhorear-se", "dominar", "conquistar", "tomar posse". São definições que diferem do verbo "emancipar", que significa, por sua vez, "tornar livre, independente". A inexistência do termo "empoderamento" na língua portuguesa e a diversidade de sentidos do termo "apoderamento" ilustram a dificuldade de realizar a tradução fidedigna de "empowerment" para o nosso idioma. ${ }^{15}$

No trabalho desenvolvido junto à Associação de Produção "Mulheres Perseverantes" utilizamos a palavra empoderamento para designar a passagem de um estágio de submissão e autoestima baixa para um estágio no qual as mulheres, mediante o processo de organização, da geração de renda e discussões sobre as relações de gênero, pudessem sentir-se capazes de mudar suas vidas através da conquista de sua autonomia pessoal, na relação com a família, contribuindo para a transformação do contexto em que estão inseridas, no caso, o Parque Eliane e, nesse processo, ir conquistando sua emancipação.

\section{Educação, diversidade e extensão: onde acontece o encontro?}

A extensão universitária poderá tornar-se um encontro entre a educação e a diversidade. Esse espaço deve ser construído com base em princípios que conduzam alunos/as, professores/as e a comunidade à emancipação. Deve ser um espaço de troca de experiência entre saberes construídos pelos sujeitos das universidades e das comunidades nas quais são desenvolvidos os projetos. Deve ser o lócus privilegiado de reflexão sobre os conhecimentos produzidos academicamente, assim como o momento de integração entre ensino, pesquisa e extensão. 
Nesse sentido, a extensão deve promover a cidadania e contribuir para a socialização de saberes e conhecimentos. Entendida como um conjunto de práticas educativas deve fazer com que a universidade seja vista como sujeito social, devendo, portanto, inserir-se na sociedade. A universidade com esse procedimento está [...] cumprindo seus objetivos de produtora e difusora de ciência, arte, tecnologia e cultura compreendidas como um campo estratégico vital para a construção da cidadania”. A partir de uma auto-reflexão, a universidade deve possibilitar esse intercâmbio entre si mesma e a sociedade, contribuindo para a construção de uma cultura de cidadania. É diretriz daquele encontro que "as atividades de extensão devem voltar-se prioritariamente para os setores da população que vêm sendo sistematicamente excluídos dos direitos e da compreensão de cidadania. ${ }^{16}$

Desse modo, a extensão pode ser vista, ainda, como processo educativo, cultural, científico e tecnológico que articula o ensino e pesquisa de forma indissociável, viabilizando a relação transformadora entre a universidade e a sociedade. ${ }^{16}$

$\mathrm{Na}$ perspectiva, a extensão pode ser exercida com um duplo caráter: o eventual e o permanente. O caráter eventual da extensão é compreendido como a realização de atividades esporádicas que estão voltadas ao aperfeiçoamento e à atualização de conhecimento. Visa também à implementação de práticas objetivando a produção técnico-científica, cultural e artística. Essas práticas podem estar voltadas a "serviços educativos, assistenciais e comunitários”. O caráter permanente, por sua vez, é aquele conjunto de atividades já elencado acima, mas que adquiriram formas sistematizadas e de maior duração em relação ao tempo de execução. ${ }^{16}$

No entanto, nossa atenção deve estar voltada para o que representa o conceito de extensão, pois, ao desenvolvermos projetos dessa natureza, corremos o risco de nos comportar como aqueles que detêm o saber e assim devemos levar o conhecimento aos que pensam que nada sabem. ${ }^{11}$ Os intelectuais, os universitários, muitas vezes, sem o perceber, veem a população com que trabalham na condição de objeto e aos poucos vão 
perdendo a oportunidade de enriquecer-se com o saber do/a outro/a, um saber diferente, mas, indiscutivelmente rico e portador da experiência do cotidiano. ${ }^{17}$

$\mathrm{Na}$ concepção de educação libertadora há necessidade de uma relação dialógica entre sujeitos, sujeitos que pensam e trocam saberes, o que indica um caminho mais coerente para a extensão. Extensão, na visão de Freire, diz respeito à transmissão, entrega, doação, messianismo, mecanicismo, invasão cultural, manipulação, superioridade - de quem entrega o conteúdo, inferioridade dos que recebem e funcionam como recipiente do conteúdo. ${ }^{18}$ Destacava que, aqueles que participam da ação com comunidades na condição de agentes sociais têm de ter a tarefa de comunicação e não de extensão. Comunicação, como ação e reflexão entre semelhantes, portadores, contudo, de formas de saber diferenciado. ${ }^{17}$ Assim, enfatizava [...] ao contrário, educar e educar-se na prática da liberdade, é tarefa daqueles que sabem que pouco sabem - por isso sabem que sabem algo e podem assim chegar a saber mais - em diálogo com aqueles que, quase sempre, pensam que nada sabem, para que estes, transformando seu pensar que nada sabem em saber que pouco sabem, possam igualmente saber mais. ${ }^{11}$

No processo de educar, os sujeitos educam-se e constroem conhecimento. Aqui, "não se estende do que se julga sabedor até aqueles que se julga não saberem; o conhecimento se constitui nas relações homem[mulher]mundo, relações de transformações e se aperfeiçoa na problematização crítica destas relações”. ${ }^{11}$

Considerando essas discussões, podemos afirmar que, através da extensão é possível promover o encontro entre a educação e as diversidades e que nesse espaço professores/as e alunos/as se (re) encontram com as vivências e práticas do cotidiano das comunidades e grupos envolvidos. Assim, esse encontro é a possibilidade de conhecer e vivenciar experiências diversas haja vista ser esse um espaço diverso.

Assim, a diversidade cultural, política, econômica, ambiental e educativa existente nos espaços de desenvolvimento dos projetos de extensão precisa ser compreendida como o encontro possível entre educação e as novas práticas educativas e sociais. 
Tal perspectiva está relacionada com a capacidade de reconhecer as diversidades cultural, étnica, religiosa, de gênero e de orientação sexual que permeiam o tecido social. A extensão poderá criar espaço de (re) encontro entre os diferentes sujeitos, de diálogo e troca de experiência, favorecendo tanto a compreensão mais aprofundada das diferenças culturais, quanto a reconstrução de valores, hábitos e saberes entre os sujeitos.

A partir dessas discussões, podemos afirmar que o encontro/reencontro entre educação e as diversidades acontece nos diversos espaços de aprendizagem e nas práticas educativas cotidianos que ocorrem tanto na universidade - espaço da educação escolar formal, quanto através dos projetos e programas de extensão - espaço da educação não escolar. Essas possibilidades podem proporcionar o saber conviver a partir da vivência de novas práticas, comportamentos, atitudes, ações de prevenção e de combate às discriminações e às injustiças. Para tanto, temos que imaginar uma sociedade plural, multicultural, capaz de administrar a igualdade e a justiça na diversidade cultural; uma sociedade aberta e tolerante diante das pluralidades que nos oferecem as sociedades multiculturais e que ultrapassam as fronteiras culturais e as antigas fronteiras sociais. Devemos tomar consciência das migrações, concebidas como um elemento constitutivo da história da humanidade, desde o princípio de nossa existência, até nossos dias. ${ }^{19}$

Assim, professores/as, alunos/as e demais participantes desses processos, após tomarem consciência da riqueza que é viver em um país cheio de diversidades poderão transformarse em pessoas mais humanas e solidárias. Para que isto ocorra, devemos construir processos formativos multiculturais capazes de preparar os/as docentes para o desenvolvimento de estratégias didático-pedagógicas que favoreçam a inclusão dos diferentes sujeitos [...], através de uma metodologia que transforme as diferenças em possibilidades de construção de novos saberes e valores voltados para o respeito, a tolerância e a convivência democrática entre grupos sociais distintos. ${ }^{20}$

É necessário, também, envolver os/as professore/as com a pesquisa, tendo em vista que os/as docentes necessitam desenvolver um olhar crítico e investigativo sobre os contextos socioculturais nos quais estão atuando, e até mesmo sobre suas próprias práticas para 
poder desenvolver processos educativos cada vez mais comprometidos com a emancipação de si, dos/as alunos/as e das comunidades.

\section{Considerações finais}

Dialogar sobre educação, diversidades, extensão e suas implicações na prática de professores/as é um desafio. Tratar desse tema é, necessariamente, pensar sobre que universidade estamos construindo e em que perspectiva estamos formando professores/as para atuar numa sociedade tão complexa como a atual. Penso que, fazer extensão é aprender a relacionar-se com o diferente. É acima de tudo socializar conhecimentos e saberes construídos historicamente.

Assim, entendemos que é extremamente importante destacar como desafios tanto para as universidades quanto para a extensão, a necessidade urgente em discutirmos que prioridades estamos dando à extensão, qual a política das universidades para essas ações, que recursos são destinados. E para concluir deixamos o seguinte questionamento: a extensão que desenvolvemos ou pretendemos desenvolver é de fato extensão?

\section{Referências}

1. BRASIL. Lei n. 9.394, de 20 de dezembro de 1996. Estabelece as diretrizes e bases da educação nacional. Diário Oficial. República federativa do Brasil, Brasília, 23 dez. 1996.

2. LIBÂNEO, José Carlos. Didática. São Paulo: Cortez, 1994.

3. CUÉLlAR, J. P. de. Nossa diversidade criadora: Relatório da Comissão Mundial de Cultura e Desenvolvimento - Unesco. Tradução de Alessandro Warley Candeas. Ministério da Cultura, 1997.

4. HALL, S. Da diáspora: identidades e mediações culturais. Belo Horizonte: Ed. UFMG; Brasília: Unesco, 2003.

5. SILVA, Maria Vieira da. O enfoque do negro no currículo escolar: algumas possibilidades de resignificação. Revista de Educação Popular, Uberlândia, n. 03, 2004.

6. BANIWA, Gersem Luciano. Proteção e fomento da diversidade cultural e os debates internacionais - a ótica dos povos indígenas. Disponível em http://www.casaruibarbosa.gov.br/dados/DOC/palestras/Diversidade_Cultural/FCRB_ DiversidadeCulturalBrasileira_GersemBaniwa.pdf. Acesso em 18 set. 2011. 
7. LOURO, Guacira Lopes. Gênero, Sexualidade e Educação: Uma perspectiva pósestruturalista. Petrópolis - RJ: Vozes, 1997.

8. SARDENBERG, Cecilia. "Pedagogias feministas: uma introdução". In.: VANIN, Iole \& GONÇALVES, Terezinha. Caderno Gênero e Trabalho. REDOR. Salvador: 2006.

9. KOROL, Claudia. "La educación como práctica de la libertad". In.: Hacia una pedagogía feminista - Géneros y educación popular. El Colectivo, América. Libre, 2007.

10. SAFFIOTI, Heleieth Iara Bongiovani. Gênero, patriarcado, violência. São Paulo: Perseu Abramo, 2004.

11. Freire, Paulo. Extensão ou comunicação? Paz e Terra, Rio de Janeiro, 1979.

12. OlIVEIRA, Maria Lúcia Lopes de. Transformaçôes das Desigualdades de Gênero? Narrativas da vida cotidiana e empoderamento de mulheres de Assentamentos do Cariri Paraibano. 169f. Dissertação (Programa de Pós-Graduação em Educação da UFPB). João Pessoa/Paraíba, 2007.

13. GOHN, Maria da Glória. Movimentos Sociais e Educação. 2a Ed. São Paulo: Cortez, 1994.

14. BECKER, Daniel, et al. "Empowerment e avaliação participativa em um programa de desenvolvimento local e promoção da saúde”. Ciência e saúde coletiva, v. 9, n.3, 2004.

15. CARVALHO, Sérgio Resende. Os múltiplos sentidos da categoria "Empowerment" no projeto de Promoção à Saúde. Cadernos de Saúde Pública, v. 20, n. 4. Rio de Janeiro, 2004.

16. MELO NETO, José Francisco de. Extensão Universitária: bases ontológicas. In. MELO NETO. José Francisco de (Org.) Extensão Universitária: diálogos populares. João Pessoa: EDUFPA, 2002.

17. ROCHA, Roberto Mauro Gurgel. Extensão Universitária e Saber Popular. In. MELO NETO. José Francisco de (Org.). Extensão Universitária: diálogos populares. João Pessoa: EDUFPA, 2002.

18. FREIRE, Paulo. Pedagogia da autonomia: saberes necessários à prática educativa. $8^{a}$ edição, Paz e Terra: Rio de Janeiro, 1998.

19. MARÍN, José. Globalização, diversidade cultural e desafios para a educação. Revista de Educação Pública. Cuiabá, v. 16, n. 30, p. 139-160, jan.-abr. 2007. 
20. LIMA, Elmo de Souza. Multiculturalismo, Currículo e Formação Docente: Construindo diálogos entre as diversidades no contexto das práticas educativas. Linguagem, Educação e Sociedade (UFPI), v. único, p. 15-31, 2010. 